\title{
Bus Device
}

National Cancer Institute

\section{Source}

National Cancer Institute. Bus Device. NCI Thesaurus. Code C49852.

A set of electrical conductors designed to route data from multiple locations in a computer. 